\title{
Conventional versus Minimally Invasive Vein Harvesting: A Clinical Audit of Wound Dehiscence Complications
}

\author{
See Woan Shiang, Simon Jerome Vendargon and Syed Rasul Bin Ghouse Syed Hamid
}

\begin{abstract}
Objective: To determine the wound complications post coronary artery bypass graft surgery (CABG) by conventional vein harvest technique $(\mathrm{CVH})$ and minimally invasive vein harvest technique (MIVH) in Hospital Sultanah Aminah Johor Bahru, Malaysia.

Study Design: Clinical audit report.

Place and Duration of Study: Hospital Sultanah Aminah Johor Bahru, Malaysia, from March 2016 to May 2017.

Methodology: Data were collected retrospectively from all 127 patients who underwent CABG with saphenous vein grafts, either with $\mathrm{CVH}$ technique $(n=68)$, or MIVH technique $(n=59)$ performed with Vasoview system. The rate of wound dehiscence was evaluated. Patients with severe wound dehiscence that required readmission and surgical intervention were identified for further evaluation.

Results: There was total $26.8 \%$ of wound dehiscence in our study, which was not appreciably different between two groups $(p=0.092)$. Patient with severe wound breakdown that required surgical intervention was significantly less in MIVH group $(1 / 59,1.7 \%)$ compared to $\mathrm{CVH}$ group $(8 / 68,11.8 \%, \mathrm{p}=0.037)$. There was no significant difference in readmission rate between MIVH and $\mathrm{CVH}$ group $(p=0.574)$.

Conclusion: There is significant reduction in severity of wound dehiscence post-saphenous vein harvesting among CABG patients with MIVH technique. However, there is no statistical difference in wound dehiscence and readmission rate between MIVH and $\mathrm{CVH}$ technique.
\end{abstract}

Key Words: Wound dehiscence, Conventional vein harvesting, Minimally invasive vein harvesting, Endoscopic vein harvesting, Wound complications.

\section{INTRODUCTION}

Coronary artery bypass grafting surgery is the operation most commonly performed in cardiac surgery. ${ }^{1}$ Despite multiple types of arterial conduit available, the long saphenous vein is still the most favourable conduit for revascularization in coronary artery bypass grafting surgery. ${ }^{2}$

Long saphenous vein harvesting with conventional harvest technique uses traditional open technique with continuous longitudinal incision or skin bridging technique with multiple small incisions. It is often associated with limb morbidity with impaired wound healing, occurring in $1-25 \%$ of patients.2,3 Major complications like sepsis and limb amputation have also been reported. 4

MIVH have been associated in significant reduction of leg wound infection rate following long saphenous vein harvesting.3,5,6 This technique was introduced at Cardiothoracic Surgery Hospital, Sultanah Aminah Johor Bahru, Malaysia since 2016. However, its effectiveness

Department of Cardiothoracic Surgery, Hospital Sultanah Aminah Johar Bahru, Johor, Malaysia

Correspondence: Dr. See Woan Shiang, Hospital Sultanah Aminah, Johor Bahru, Johor, Malaysia

E-mail: seewoanshiang@gmail.com

Received: June 19, 2018; Accepted: October 18, 2018 in reducing wound dehiscence rate post-surgery has never been assessed.

The aim of this retrospective study was to compare the lower limb wound dehiscence rates between $\mathrm{CVH}$ technique and $\mathrm{MIVH}$ technique for long saphenous vein harvesting in CABG patients.

\section{METHODOLOGY}

The research protocol was approved by Malaysia Ministry of Health, Malaysia Medical Research Ethic Committee and National Research Center.

All patients in Hospital Sultanah Aminah Johor Baru, Malaysia who had undergone coronary artery bypass grafting surgery (CABG) with use of saphenous vein grafts (SVGs) from March 2016 to May 2017 were included into the study, with total number of 127 patients. Their medical records were collected and reviewed. These patients were then divided into two groups, $\mathrm{CVH}$ and MIVH group, based on the vein harvesting technique done. The harvesting technique was decided based on operating surgeon's preference. $\mathrm{CVH}$ group $(n=68)$ had conventional open saphenous vein harvesting. MIVH group had minimally invasive endoscopic saphenous vein harvesting. All deaths were excluded from the study.

Vein harvesting was performed by experienced medical assistants. Perioperative care was similar for all patients. 
Both the long saphenous vein harvesting procedures were performed by an experienced surgical assistant, who had done similar procedures since past one year.

By continuous longitudinal incision technique, the incision started one centimeter above and lateral to the medial malleolus and carried on along the whole course of the long saphenous vein in different length varieties depending on the amount of vein required.

On the other hand, skin bridging technique was done with multiple $3-5 \mathrm{~cm}$ incisions, leaving in between a distance of 6-8 $\mathrm{cm}$ skin bridge.

After hemostasis, the incision was cleaned with povidone. The closure was performed with $2 / 0$ vicryl sutures for the subcutaneous layer and monosyn 4/0 sutures for the subcuticular layer. No drain was inserted. A dry dressing was applied and wrapped with a crepe bandage for 3 days.

By endoscopic vein harvesting, the vein was harvested using the VasoView system. The procedure was performed by making a 1-2 cm transverse incision just below knee and the vein is identified. After carbon dioxide insufflation, a dissection cannula was inserted and followed distally to the lower leg to isolate the vein and its branches. The tributary branches were cauterized and cut. An incision about 1-2 cm was made at the lower leg to expose the end of the vein for ligation. The instruments were then inserted into the initial incision and the vein was followed proximally to isolate the proximal vein. A 1-2 cm incision was made at the medial thigh for vein ligation. The wound closure and postoperative care were similar to the conventional method, which was the standard procedure for vein harvesting.

The surgical wound was inspected 5 days after surgery by the surgeon during hospitalization, and subsequent wound inspection was done at 1 week, 6 weeks and 3 months after discharge at outpatient clinic by cardiothoracic surgery medical officers. Patients were advised to bathe twice daily and clean the wound with soap at home upon discharge. Wound dehiscence was defined as wound edge separation that required a minimum of wet to dry dressing changes. ${ }^{6}$

All data are analyzed using SPSS version 17.0. Descriptive and cross tabulation analyses were used for distribution of patient's socio-demographic background at baseline with student's t-test to analyze the continuous variables. Pearson chi square analysis is used to analyse the rate of post-long saphenous vein harvesting wound dehiscence for minimally invasive vein harvest technique and conventional vein harvest technique. Multiple logistic regression is performed to assess the association of each independent variables for wound dehiscence. A p-value of $<0.05$ was considered statistically significant.

\section{RESULTS}

One hundred and twenty-seven patients were included, while three patients were excluded due to early postoperative death from cardiac arrhythmia, severe acute respiratory distress syndrome, and severe pneumonia. The baseline characteristics of the patients from each group were compared. There was no statistical significance in baseline characteristic differences, as shown in Table I.

The mean age for $\mathrm{CVH}$ and $\mathrm{MIVH}$ groups were not statistically different ( $56.15 \pm 8.82$ vs. $54.36 \pm 7.62$ years, $p=0.570$ ). Both groups were similar in gender, race and mean BMI. Diabetic patients were in higher proportion in MIVH group, but it is not statistically significant. There were a total of $26.8 \%(34 / 127)$ of wound dehiscence in our study. The rate of wound dehiscence, readmission and requirement for surgical intervention post-harvesting wound breakdown in comparison of two groups are shown in Table II.

There were 22 (32.4\%) out of 68 patients from CVH group who developed wound dehiscence, while 12 (20.3\%) patients from MIVH group developed wound dehiscence. There was no significant statistical difference in the rate of wound dehiscence between 2 groups ( $p=0.092)$.

Readmission is required if the patients developed postlong saphenous vein harvesting wound dehiscence that required intravenous antibiotics or secondary surgical intervention. There were slight reduction in readmission for patients who underwent MIVH; however, it was not statistically significant $[(8 / 68(11.8 \%)$ vs. $5 / 59(8.5 \%)$, $\mathrm{p}=0.542)]$.

Among the readmitted patients with wound dehiscence, all eight patients from $\mathrm{CVH}$ group required surgical

Table I: Patient characteristics in the conventional and minimally invasive vein harvest technique groups.

\begin{tabular}{l|c|c|c}
\hline $\begin{array}{l}\text { Baseline } \\
\text { characteristic }\end{array}$ & $\begin{array}{c}\text { CVHT Group } \\
\mathrm{n}=68\end{array}$ & $\begin{array}{c}\text { MIVHT Group } \\
\mathrm{n}=59\end{array}$ & $\mathrm{p}$-value \\
\hline $\begin{array}{l}\text { Gender } \\
\text { Male }\end{array}$ & $64 / 68(94.1 \%)$ & $54 / 59(91.5 \%)$ & 0.570 \\
Female & $4 / 68(5.9 \%)$ & $5 / 59(8.5 \%)$ & \\
\hline Age & $56.15 \pm 8.82$ & $54.36 \pm 7.62$ & 0.057 \\
\hline Race & & & \\
Malay & $35 / 68(51.5 \%)$ & $23 / 59(39 \%)$ & 0.116 \\
Chinese & $19 / 68(27.9 \%)$ & $27 / 59(45.8 \%)$ & \\
Indian & $14 / 68(20.6 \%)$ & $8 / 59(13.6 \%)$ & \\
\hline Diabetes mellitus & $27 / 68(39.7 \%)$ & $27 / 59(45.8 \%)$ & 0.490 \\
\hline BMI & $26.14 \pm 3.83$ & $26.17 \pm 3.91$ & 0.680 \\
\hline
\end{tabular}

Table II: Rate of wound dehiscence, readmission and surgical intervention requirement among CABG patients with post-harvesting wound complication.

\begin{tabular}{l|c|c|c}
\hline $\begin{array}{l}\text { Wound dehiscence } \\
\text { complication }\end{array}$ & $\begin{array}{c}\text { CVHT } \\
\mathrm{n}=68\end{array}$ & $\begin{array}{c}\text { MIVHT } \\
\mathrm{n}=59\end{array}$ & $\mathrm{p}$-value \\
\hline Wound dehiscence & $22 / 68(32.4 \%)$ & $12 / 59(20.3 \%)$ & 0.092 \\
Readmission & $8 / 68(11.8 \%)$ & $5 / 59(8.5 \%)$ & 0.542 \\
Surgical intervention & $8 / 68(11.8 \%)$ & $1 / 59(1.7 \%)$ & 0.027 \\
\hline
\end{tabular}




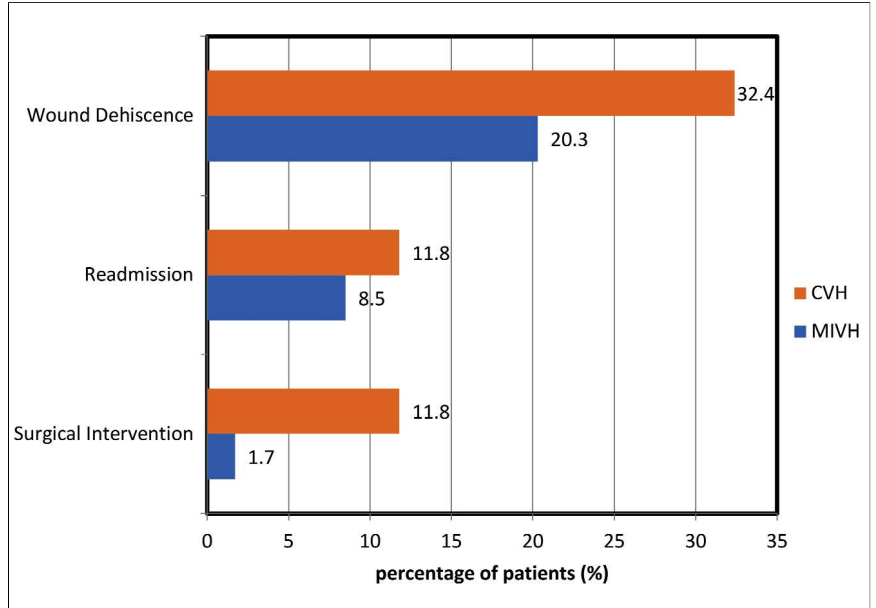

Figure 1: Comparison of wound dehiscence, readmission and surgical intervention rate for post-vein harvesting wound complication.

intervention for wound management. The surgical interventions include surgical debridement, secondary suturing and plastic surgeon referral for split skin grafting. The rate of surgical intervention is significantly reduced in $\mathrm{MIVH}$ group, in which only one patient required surgical intervention $(8 / 68[(11.8 \%)$ vs. $1 / 59$ $(1.7 \%), p=0.027)]$.

\section{DISCUSSION}

Lower limb wound complications are common among post-CABG patients. Wound dehiscence, readmission, and further surgical intervention are important indicators for severe wound complication in bypass surgery. It is associated with increased hospital stay which affects financial burden in both healthcare taker and patients. ${ }^{7}$ Total cost for wound management has tremendously increased compared to the equipment cost of endoscopic vein harvesting technique.2,3 As compared to various previous studies, which had proven wound complication reduction among bypass surgery patients with MIVH; in this study, the wound dehiscence rate was not significantly different in $\mathrm{CVH}$ and MIVH groups ( $32.4 \%$ vs $20.3 \%$ ). However, it is likely due to the small sample size $(n=127)$ in this study.

The requirement of surgical intervention for wound dehiscence post-LSV harvesting was significantly higher among the CVH group as compared to MIVH group $(11.8 \%$ versus $1.7 \%)$. Therefore, minimally invasive vein harvesting technique may significantly reduce the extra cost needed for wound complication management. Similar study by Crouch et al. showed that minimally invasive vein harvesting technique had reduced wound complications by $60 \%$, which can significantly reduce the additional costs as a result of additional admissions, wound care, debridement, skin grafting surgery, and antibiotic use. It is also associated with improved patient's satisfaction. 3,7

The proposed theory for the lower wound complication with MIVH is the smaller incision and better preserved tissue perfusion, which results in better wound healing. It is also associated with less traumatic surrounding tissue injury and skin flap creation. 8 it is particularly important among patients with diabetes mellitus, peripheral vascular disease, obesity and female gender, which are at high risk of developing post-harvesting wound break-down. International Society of Minimally Invasive Cardiac Surgery (ISMICS) recommends MIVH use in CABG patients with LSV harvesting for improvement of satisfaction post-surgery and lower limb complications, with preservation of vein graft quality. 2,9

The main limitation in this study is the small sample size as compared to previous studies. Our study aims to assess the efficacy of MIVH in reducing the wound dehiscence rate among CABG patients with LSV graft in Malaysia and ASEAN population. Up-to-date, post CABG lower limb complications have never been studied in our region. Thus, we would recommend further studies to compare MIVH and $\mathrm{CVH}$ with larger sample size

Besides post-harvesting wound complications, graft patency and quality are another concern among surgeons when applying MIVH in bypass surgery, which is not covered in this study.9,10 The author would suggest further studies to be carried out to assess the LSV graft quality with MIVH in bypass surgery.

Other factors which are associated with post-harvesting wound complication include the length of time of surgery, ICU stay, operator factor, and graft length.11,12 Further studies into these sectors are required. $13,14,15$

\section{CONCLUSION}

There is significant reduction in severity of wound dehiscence post-saphenous vein harvesting among CABG patients with MIVH technique. However, there is no statistical difference in wound dehiscence and readmission rate between $\mathrm{MIVH}$ and $\mathrm{CVH}$ technique.

\section{REFERENCES}

1. Department of Statistics Malaysia, Official Portal. Statistics on causes of death, Malaysia, 2014.

2. Waqar-Uddin Z, Purohit $\mathrm{M}$, Blakeman $\mathrm{N}$, Zacharias J. A prospective audit of endoscopic vein harvesting for coronary artery bypass surgery. Ann R Coll Surg Engl 2009, 91: 426-9.

3. Crouch JD, O'Hair DP, Keuler JP, Barragry TP, Werner PH, Kleinman LH. Open versus endoscopic saphenous vein harvesting: wound complications and vein quality. Ann Thorac Surg 1999; 68:1513-6.

4. Paletta CE, Huang DB, Fiore AC, Swartz MT, Rilloraza FL, Gardner JE. Major leg wound complications after saphenous vein harvest for coronary revascularization. Ann Thorac Surg 2000; 70:492-7.

5. Athanasiou T, Aziz O, Skapinakis P, Perunovic B, Hart J, Crossman MC, et al. Leg wound infection after coronary artery bypass grafting: A meta-analysis comparing minimally invasive versus conventional vein harvesting. Ann Thorac Surg 2003; 76:2141-46. 
6. Bitondo JM, Daggett WM, Torchiana DF, Akins CW, Hilgenberg $A D$, Vlahakes GJ, et al. Endoscopic versus open saphenous vein harvest: A comparison of postoperative wound complications. Ann Thorac Surg 2002; 73:523-8.

7. Luckraz $H$, Kaur P, Bhabra M, Mishra PM, Nagarajan K, Kumari N, et al. Endoscopic vein harvest in patients at high risk for leg wound complications: A cost-benefit analysis of an initial experience. Am J Infect Control 2016; 44:1606-10.

8. Raja SG, Sarang Z. Endoscopic vein harvesting: technique, outcomes, concerns \& controversies. J Thorac Dis 2013; 5: 630-7.

9. Sastry P, Rivinius R, Harvey R, Parker RA, Rahm AK, Thomas D, et al. The influence of endoscopic vein harvesting on outcomes after coronary bypass grafting: A meta-analysis of $267-525$ patients. Eur J Cardiothorac Surg 2013; 44:980-9.

10. Andreasen JJ, Vadmann $\mathrm{H}$, Oddershede L, Tilsted $\mathrm{HH}$, Frokjaer JB, Jensen SE. Decreased patency rates following endoscopic vein harvest in coronary artery bypass surgery. Scand Cardiovasc J 2015; 49:286-92.
11. Khan Jk, Shahabuddin S, Khan S, Bano G, Hashmi S, Sami SA. Coronary artery bypass grafting in South Asian patients: Impact of gender. Ann Med Surg 2016; 9:33-7.

12. Ahmed D, Cheema FH, Ahmed YI, Schaefle KJ, Azam SI, Sami SA, et al. Incidence and predictors of infection in patients undergoing primary isolated coronary artery bypass grafting: a report from a tertiary care hospital in a developing country. J Cardiovasc Surg (Torino) 2011; 52:99-104.

13. Au WK, Chiu SW, Sun MP, Lam KT, Lin MF, Chui WH, et al. Improved leg wound healing with endoscopic saphenous vein harvest in coronary artery bypass graft surgery: A prospective randomized study in Asian population. $J$ Card Surg 2008; 23: 633-7.

14. Ziauddin AK, Mudassir ID, Farha I, A.Qadeer K, Aneela H. Incidence of complications after cardiac surgery, single unit experience. Pak Heart J 2008; 41:41-8.

15. Hamid T, Malik N. Saphenous vein graft pseudoaneurysm: A case for medical management. J Coll Physicians Surg Pak 2014; 24:169-70. 